\title{
Terapia ocupacional, a produção do cuidado em saúde e o lugar do hospital: reflexões sobre a constituição de um campo de saber e prática*
}

\section{Occupational therapy, the production of health care and the place occupied by the hospital: thoughts about the constitution of a field of knowledge and practice}

\author{
Sandra Maria Galheigo ${ }^{1}$
}

\begin{abstract}
GALHEIGO, S. M. Terapia ocupacional, a produção do cuidado em saúde e o lugar do hospital: reflexões sobre a constituição de um campo de saber e prática. Rev. Ter. Ocup. Univ. São Paulo, v.19, n. 1, p. 20-28, jan./abr. 2008.

RESUMO: Este artigo se propõe a problematizar a existência de um campo específico de terapia ocupacional em práticas hospitalares e sua relação com a produção de saberes e práticas relativas ao cuidado em saúde. A partir da discussão do conceito de campo em Bourdieu e segundo Campos, Chakour e Santos, o texto busca discutir a produção da saúde como campo dinâmico, interdisciplinar e estruturado, constituído pelas relações entre diferentes instituições, núcleos profissionais, grupos internos e agentes sociais que o compõem. As reflexões apontam na direção de pensarmos o lugar do hospital e suas práticas de dentro do campo da produção do cuidado em saúde, no qual a terapia ocupacional é um dos núcleos profissionais. Assim, as práticas privativas e compartilhadas dos vários núcleos profissionais no hospital, não devem ser pensadas fora do contexto mais amplo do campo, se se quer construir a integralidade do cuidado a partir da perspectiva do hospital como uma 'estação do cuidado'. Apresentando a proposta de gestão hospitalar segundo linhas do cuidado, desenvolvida por Cecílio e Mehry, o artigo propõe sua utilização enquanto principio de organização dos saberes e práticas da produção de saúde e da própria terapia ocupacional, na busca de ações que sejam efetivamente fundadas na integralidade e na humanização do cuidado.
\end{abstract}

DESCRITORES: Terapia ocupacional. Processo saúde-doença. Assistência integral à saúde. Assistência hospitalar. Humanização da assistência.

\footnotetext{
* Artigo produto de projeto de pesquisa Práticas hospitalares em terapia ocupacional: um estudo sobre a consolidação do campo no Estado de São Paulo, que a pesquisadora vem desenvolvendo com o apoio do CNPq.

1. Professora doutora, docente do Departamento de Fisioterapia, Fonoaudiologia e Terapia Ocupacional da Faculdade de Medicina da USP.

Endereço para correspondência: Centro de Docência e Pesquisa em Terapia Ocuapcional da FMUSP. Rua Cipotânea, 51 - Cidade Universitária, 05508-900, São Paulo-SP.
} 


\section{INTRODUÇÃO}

$\mathrm{E}$ studar a constituição do campo da produção da saúde e da participação do terapeuta ocupacional enquanto agente deste campo requer abordar como vem sendo construída a produção de saberes e práticas neste domínio. Pensar a constituição dos campos específicos da terapia ocupacional implica, portanto, em inscrever o debate no diálogo epistemológico mais amplo, contextualizando os processos históricos que permeiam a fundação da profissão, o desenvolvimento de suas práticas e suas reorganizações.

Para começar, estudar a constituição dos campos na terapia ocupacional no Brasil nos remete à primeira fase da produção das práticas e saberes da profissão que, grosso modo, se deu dos 1950s aos 1980s. Neste período, partia-se de uma definição nuclear única da terapia ocupacional, que era então 'aplicada' às especialidades médicas, doenças, doentes, deficiências e condições. Foram os tempos da Terapia Ocupacional aplicada à Neurologia, a Terapia Ocupacional aplicada à artrite reumatóide, ao deficiente mental, às condições sociais, para citar alguns.

A reorganização das políticas públicas e da assistência no Brasil, que começou a ganhar forma a partir de meados dos anos 1980, permitiu re-configurar os saberes e práticas da terapia ocupacional em novos campos de legitimidade. Mângia argumenta que os campos na terapia ocupacional passaram então a ser constituídos a partir das demandas das populações e de sua capacidade de negociação por serviços e bens sociais, das dinâmicas e particularidades do mercado de trabalho e da construção de discursos e diálogos com as demais profissões (MÂNGIA, 1998). A partir dos 1990s, a tarefa tem sido, portanto, a da consolidação dos campos específicos da terapia ocupacional, que depende da interconexão de vários fatores, a saber: sua contextualização histórico-política; a fundamentação de suas bases conceituais e metodológicas; sua consonância com as políticas setoriais; sua legitimação pelos pares e pelos demais profissionais dos setores saúde, educação, assistência social e trabalho; e as peculiaridades de suas práticas e intervenções, privativas ou compartilhadas com os demais profissionais (GALHEIGO, 1999).

$\mathrm{Na}$ primeira década do novo milênio, e a cinqüenta anos da criação da profissão no país, a terapia ocupacional tem alguns campos com territórios suficientemente demarcados, com produções científicas constantes e com práticas suficientemente legitimadas (mesmo que ainda prioritariamente pelos próprios profissionais). Os campos usualmente denominados como Saúde Mental, Saúde e Trabalho, Gerontologia, Reabilitação da pessoa com deficiência, e
Terapia Ocupacional Social, seguem este padrão e, mesmo com variações de denominação e de abrangência nacional, apresentam coerência interna no que diz respeito à população atendida, às políticas sociais a que se filiam e aos grupos profissionais com quem dialogam. De fato, mesmo que haja princípios norteadores e metodologias de ação divergentes dentro de um mesmo campo, o reconhecimento de uma determinada identidade, população-destino e necessidades sociais e de saúde garante sua configuração.

A intervenção da terapia ocupacional nos processos saúde-doença, principalmente aqueles ligados aos transtornos orgânicos, que requerem cuidados de clínica médica e cirúrgica, começou mais recentemente a ser reconhecida como campo e tem sido referida, em algumas esferas, como campo da terapia ocupacional nas práticas (ou nos contextos) hospitalares. Se há consenso nessa denominação, no que se espera como papel da terapia ocupacional no hospital contemporâneo, ou no reconhecimento dessas práticas como 'campo' ainda está por se estabelecer, sendo proposta deste artigo realizar algumas incursões sobre esse debate.

Analisando a produção do conhecimento nas práticas hospitalares, encontramos maior regularidade em alguns domínios, a saber: neonatologia e saúde materno-infantil, cuidado à criança e ao adolescente hospitalizados, atendimento ao adulto e ao idoso no hospital geral e intervenção com as pessoas com câncer e HIV/AIDS. Na análise de conteúdo dessa produção nos deparamos com uma diversidade de compreensões do que seria a terapia ocupacional neste âmbito, que elencam: ações de recuperação da capacidade funcional; ações de promoção à saúde materno-infantil, desenvolvidas via de regra na atenção básica à saúde; ações fundadas na abordagem psicodinâmica da terapia ocupacional, dentre outras. As produções igualmente remetem a ações nos diferentes níveis de atenção - proteção, promoção, recuperação da saúde, prevenção de agravos e reabilitação. Entretanto, pouco discorrem sobre a importância da integralidade do cuidado no hospital e de sua inserção no Sistema Único de Saúde, exceto quando falam da humanização do cuidado, principalmente em enfermarias pediátricas (GALHEIGO, 2007).

Assim, retornando à reflexão se as práticas hospitalares configuram um 'campo próprio de saber e prática' em terapia ocupacional ou se são domínios do campo maior da produção do cuidado em saúde, somos remetidos à própria discussão da conceituação de campo, de como essa discussão vem sendo feita na saúde e na terapia ocupacional. Ao mesmo tempo, somos instigados a refletir sobre qual tem sido o lugar do hospital e das especialidades médicas no enfrentamento dos processos saúde-doença e na produção do cuidado no Brasil e qual tem sido (e/ou poderia ser) o 
posicionamento da terapia ocupacional frente ao debate nacional.

\section{Sobre os conceitos de campo e sua aplicação ao setor saúde}

Conforme exposto anteriormente, pensar a constituição e a consolidação de um campo de conhecimento e de práticas profissionais no setor saúde não pode estar desvinculado da compreensão histórica e política de seus saberes, práticas e das histórias das profissões. Entretanto, há diversas construções do conceito de campo, diferentes inclusive do entendimento que vem sendo usado na terapia ocupacional, sob cuja base foi apresentada a introdução acima. É o caso das contribuições de Pierre Bourdieu, nas Ciências Sociais, e de Gastão de Sousa Campos, Mauricio Chakour e Rogério de Carvalho Santos, na Saúde Coletiva. Embora diferentes entre si e da concepção inicialmente utilizada nesse artigo, as discussões sobre campo desenvolvidas por esses autores não são incompatíveis e ajudam a compreender, sob diferentes prismas, o assunto estudado.

\section{O conceito de campo em Bourdieu}

O espaço social para Bourdieu é constituído por campos sociais, relativamente autônomos, a partir dos quais a produção e a vida social, por assim dizer, se organizam. Segundo ele, pode-se assim falar em campo religioso, campo político, artístico, científico, da educação, da mídia, etc. Os campos, sob esta perspectiva, não possuem fronteiras delimitadas e articulam-se entre si, garantindo o processo de diferenciação social nas sociedades complexas. Entretanto, são microcosmos sociais, com lógicas, ordenações e necessidades específicas, irredutíveis uns aos outros (BONNEWITZ, 2003; ORTIZ, 2003).

Com seu conceito de espaço social, Bourdieu rompe com a visão tradicional da hierarquia social que se funda numa visão piramidal de sociedade. Entretanto, incorpora, nos conceitos de espaço social e campo social, a noção de conflito e estratificação social de Marx e Weber. Sua concepção de espaço social é, portanto, a de um espaço hierarquizado pela distribuição desigual dos capitais, descritos como: capital econômico (bens econômicos e de produção, força de trabalho); capital cultural (qualificação intelectual produzida pela família e pela educação); capital social (relações sociais de indivíduos, grupos e coletividades) e capital simbólico (conjunto de rituais ligados à honra, ao reconhecimento, à legitimação) (BONNEWITZ, 2003; ORTIZ, 2003).

Assim, o campo para Bourdieu, é dinâmico e estrutu- rado; as relações entre as diferentes instituições, corporações profissionais, grupos internos e agentes sociais que 0 compõem se organizam em rede. As características, regras e conformação do campo variam de acordo com suas práticas e sua histórica e, com as hierarquias e as estratégias hegemônicas ou contra-hegemônicas, utilizadas pelos seus diferentes integrantes, que estabelecem entre si um conjunto de relações de força. Seus membros podem assumir o papel de produtores, distribuidores, consumidores, legitimadores ou reguladores, e, a partir destas posições, produzir capital (e disputar poder) econômico, cultural, social e simbólico (BONNEWITZ, 2003; ORTIZ, 2003).

Aplicando a perspectiva de Bourdieu ao campo da produção da saúde, podemos compreendê-lo como um microcosmo que incorpora diferentes cenários, instituições, grupos e agentes sociais. Em linhas gerais, este campo se organiza pela ação e interação de: produtores (formuladores de política, gestores, pesquisadores, produtores de equipamentos e medicamentos, empresas médicas); distribuidores (serviços, equipamentos de atenção à saúde; profissionais de saúde, médicos e não médicos); consumidores (usuários e sua rede social) e instâncias reguladoras e legitimadoras (conselhos profissionais, associações científicas, universidades, conselhos de saúde, agência nacional de saúde). Podemos dizer que as relações mediadas pelos diferentes papéis envolvidos na produção, distribuição e consumo no campo da saúde se determinam mutuamente de acordo com suas regras e características específicas. São relações dinâmicas que ocorrem segundo determinado jogo social, que conforme mencionado acima, implica na produção e competição dos variados capitais.

Uma abordagem mais compreensiva do campo de produção da saúde parece, portanto, mais pertinente do que a própria referência a um sistema de saúde, já que um sistema subentende harmonia e consensualidade. Como CECÍLIO; MEHRY (2003) bem argumentam:

“o denominado 'sistema de saúde'é, na verdade, um campo (grifo nosso) atravessado por várias lógicas de funcionamento, por múltiplos circuitos e fluxos de pacientes, mais ou menos formalizados, nem sempre 'racionais', muitas vezes interrompidos ou truncados, construídos a partir de protagonismos, interesses e sentido que não podem ser subsumidos à uma única racionalidade institucional ordenadora. Mais do que um sistema, deveríamos pensar em uma rede móvel, assimétrica e incompleta de serviços que operam distintas tecnologias de saúde e que são acessados de forma desigual pelas diferentes pessoas e agrupamentos, que deles necessitam. (p. 3-4)".

Em síntese, as dinâmicas do campo da produção da saúde acima delineadas se traduzem nas micro-dinâmicas 
encontradas nos diferentes cenários de atenção à saúde onde seus profissionais desenvolvem suas práticas cotidianas, desenvolvem tecnologias e produzem conhecimento. Há, portanto, uma permanente colaboração e disputa entre instituições e agentes sociais, seja no âmbito da atividade científica ou da prática profissional. Os vários interesses econômicos, políticos e ideológicos, as diferentes visões de mundo e de ciência, os distintos posicionamentos éticos e projetos societários desembocam numa luta pelo monopólio da produção científica e pelo espaço corporativo, privativo do exercício profissional (VASCONCELOS, 2004).

Ao trazer esta perspectiva de campo para pensar a inserção do terapeuta ocupacional no setor saúde, somos imediatamente confrontados com a concepção idealizada da equipe multiprofissional, que ainda se reproduz no ideário da saúde. Mesmo sendo inegável que as práticas integradas potencializam as intervenções, há que se reconhecer que elas acontecem dentro de uma determinada composição de forças e a partir do desejo de uma construção compartilhada permanente, e não como resultante de um fato natural ou de um ato normativo.

Assim, a posição do terapeuta ocupacional no setor saúde, e em particular nas práticas que envolvam o cuidar nos processos saúde-doença, deve ser entendida à luz dessa composição de forças que inscreve o profissional numa determinada hierarquia do campo. Sua posição e movimento dependem do seu capital econômico, cultural, social e simbólico, das estratégias de adesão e enfrentamento da ordem social estabelecida e da consistência da reprodução social de suas práticas e saberes.

A discussão da constituição dos campos, entretanto, deve ir além da discussão da produção dos saberes e das práticas e buscar a explicitação dos diferentes interesses e projetos subjacentes aos diferentes domínios. Como aponta Vasconcelos (2004):

"Só assim as diferenças ganham plena inteligibilidade e se permite aos participantes do debate a plena compreensão e a possibilidade de um posicionamento mais crítico e consciente de suas implicações" (p. 55).

Refletir sobre a inserção do terapeuta ocupacional no campo de produção da saúde implica, portanto, conhecer os limites críticos do campo e discutir quais são os consensos possíveis e os dissensos inevitáveis que o profissional deve incorporar na produção de suas práticas e conhecimentos.

\section{O conceito de campo segundo Campos, Chakour e Santos}

Um dilema importante na organização da produção do saber e das práticas do campo da saúde é resultante da fragmentação dos saberes e práticas de saúde que aconteceu a partir da constituição do hospital como lugar hegemônico da assistência e das diferentes especialidades médicas como instrumento de sua distribuição. Com o advento da saúde coletiva na virada dos anos 80 , o social passa a ser incorporado como categoria de análise para o entendimento dos processos saúde-doença, desenvolvendo-se uma crítica a sua naturalização e ao modelo biomédico e tecno-científico de saúde. Entretanto, quando se fala na assistência hospitalar, percebe-se o quanto resta a ser discutido e implementado para a qualificação do atendimento prestado aos usuários dos hospitais públicos, apesar das mudanças propostas pelas políticas de saúde. A discussão do campo de produção da saúde revela assim suas fraturas.

Foi a crescente criação de novas especialidades médicas e sua dificuldade de inserção no Sistema Único de Saúde, gerando dificuldades para a resolutividade das ações de saúde e para a gestão dos serviços, que levou Campos, Chakour e Santos (1997) a pensarem uma alternativa que implicasse "dividir a denominada área de competência de cada especialidade em dois espaços inclusivos": os campos e os núcleos de competência. Os autores pretendiam com essa proposição pensar estratégias de enfrentamento para lidar com a tendência das novas especialidades médicas definirem um campo muito rígido de atribuições próprias, retirando atribuições das especialidades-raízes e levando à perda das habilidades médicas básicas pelo processo de criação de novas especialidades.

O campo de competência, segundo esses autores, seria mais geral, com limites e contornos menos precisos, e "incluiria os principais saberes da especialidade-raiz e (...) teria uma sobreposição de exercício profissional com outras especialidades". Já o núcleo de competência, mas específico, com uma maior delineação de definições, "incluiria as atribuições específicas daquela especialidade, justificando, portanto, sua existência como nova área" (CAMPOS et al., 1997, p. 143). Para esses autores, se adotado este critério, o campo de competência do especialista em cirurgia de mão seriam as lesões de mão e mais as práticas e saberes próximos ao do cirurgião geral. Já o núcleo de competência do especialista em cirurgia de mão seria relativo às atribuições específicas da atenção aos casos graves de trauma e lesões importantes de estruturas nobres da mão, que justificaria a necessidade da criação de uma nova especialidade.

Posteriormente, Campos (2000), em artigo sobre o campo e o núcleo de saberes e práticas da saúde coletiva, aprofunda estes dois conceitos de forma que para ele: 
"o núcleo demarcaria a identidade de uma área de saber e de prática profissional; e o campo, um espaço de limites imprecisos onde cada disciplina e profissão buscariam em outras apoio para cumprir suas tarefas teóricas e práticas (...). Tanto o núcleo quanto o campo seriam, pois mutantes e se interinfluenciariam, não sendo possível detectar-se limites precisos entre um e outro. Contudo, no núcleo, haveria uma aglutinação de saberes e práticas, compondo uma certa identidade profissional e disciplinar". (p. 220-1).

Em síntese, nessa perspectiva, o campo seria quase sempre interdisciplinar e multiprofissional e o núcleo disciplinar e profissional. Traduzindo suas reflexões para a composição do campo da saúde coletiva, Campos (2000) discute a identidade desse campo, seu espectro de interinfluência, seus agentes e seu núcleo de saber específico. Propõe que se aborde o campo da produção da saúde a partir de uma matriz em cujos planos, horizontal e vertical, se alinhariam os diferentes saberes e práticas. Defende que uma teoria sobre a produção de saúde se apóie nas diversas práticas sanitárias, apontando a necessidade de se ouvir tanto a clínica quanto a saúde coletiva, se a meta é pensar modelos e políticas de atenção integral à saúde. O artigo, entretanto, não vai além, no sentido de apresentar como as especialidades clínicas interagiriam nesta matriz, nem como seria a inserção dos demais profissionais de saúde na mesma. Ademais, a centralidade da disciplina no conceito de núcleo deixa pouca margem para se pensar em práticas de saúde que não tenham a disciplina e a categoria profissional como eixos organizadores do cuidado.

Apesar desses destaques, a discussão sobre campos e núcleos contribui para se refletir sobre as contradições e dilemas inerentes à concepção das práticas hospitalares como campo específico de saberes e práticas ao invés de tomá-las como ações de cuidado realizadas num equipamento do setor saúde - o hospital. Para dar continuidade a tais ponderações acerca da constituição dos campos é necessário, primeiro, que se possa refletir sobre o lugar do hospital e da terapia ocupacional no campo da produção da saúde.

\section{Terapia Ocupacional, a produção do cuidado em saúde e o lugar do hospital}

Para se problematizar sobre as práticas hospitalares em terapia ocupacional, há que se lembrar, antes de tudo, que foi no hospital que se deu o surgimento da própria terapia ocupacional no início do século XX, nos Estados Unidos da América e, nos meados do mesmo século, no Brasil. Entretanto, tal surgimento foi marcado pela atenção aos pacientes crônicos - psiquiátricos ou tuberculosos.

É possível falar-se, portanto, da longevidade do traba- lho do terapeuta ocupacional no hospital, mas não de que existam práticas e saberes sendo consolidados neste domínio desde então. Ao contrário, foi da crítica e desconstrução de um modelo de terapia ocupacional hospitalocêntrico, que os demais campos de conhecimento e prática da terapia ocupacional puderam se criar, favorecendo o surgimento de propostas de ação de proteção, promoção, recuperação da saúde e de reabilitação, em meio aberto, ou seja em instituições não asilares, no domicílio, na comunidade, em ambulatórios, na rede básica de assistência à saúde, nos ambientes de trabalho ou na rua. Assim, no Brasil, o processo de expansão e consolidação da terapia ocupacional em alguns destes domínios foi acontecendo de forma mais intensa do que o processo da terapia ocupacional nos contextos hospitalares, seja em volume de produção científica ou de inserção profissional na assistência.

Há, de fato, certa tensão gerada pelo fato da atuação da terapia ocupacional no hospital de agudos (para cuidados clínicos e cirúrgicos) ter se constituído ao mesmo tempo em que as medidas de desconstrução do hospital de crônicos estavam sendo implementadas e de que, tudo que se identificasse com asilamento, institucionalização e segregação, fosse firmemente negado enquanto possibilidade, humanamente aceitável, do cuidado. Leia-se aqui, não apenas a hospitalização e o asilamento de loucos, como o de idosos, hansenianos, pessoas com deficiências físicas e mentais, e de crianças, jovens e adultos em situação de vulnerabilidade.

Por outro lado, o fato de o hospital ser identificado com o local da hegemonia médica e da intervenção especializada, foi fator igualmente importante para o distanciamento crítico de alguns terapeutas ocupacionais, que não se alinhavam com ações construídas a partir do processo crescente da hiperespecialização do conhecimento e da fragmentação do fazer que rege a lógica da atenção por procedimentos, a despeito das necessidades concretas do sujeito-foco do cuidado. Sem dúvida, houve um movimento contrahegemônico de terapeutas ocupacionais que buscaram a construção de saberes e práticas no hospital baseadas em concepções holísticas e no princípio da integralidade já nascente nos debates da reforma sanitária. Entretanto, a própria re-ordenação do mercado de trabalho e a dificuldade de implantação de serviços de terapia ocupacional em hospitais, contribuíram para que tais movimentos ficassem reduzidos a alguns nichos no país.

O movimento atual requer, portanto, recolocar a atenção da terapia ocupacional no hospital contemporâneo, a partir de outro 'lugar', isto é, situá-la no cerne do campo da produção do cuidado em saúde, retomando a discussão do lugar do hospital na configuração do Sistema Único de 
Saúde e da integralidade como eixo do cuidado.

É importante que se reconheça que o hospital contemporâneo tem passado por desafios importantes colocados pela transição epidemiológica e o envelhecimento populacional, pela complexificação da atenção oferecida e pelo aumento da sobrevida dados os avanços tecnológicos. Assim, o hospital passa a ser visto como o lugar da atenção de alta-complexidade, onde os transplantes, as cirurgias cardíacas, os cuidados intensivos e os tratamentos de ponta são sua melhor expressão. Entretanto, é importante que não se esqueça que o hospital continua sendo uma importante porta de entrada do sistema, já que ele é o espaço da manifestação tanto da falta de acesso à atenção básica à saúde, à educação e à proteção social como da precariedade das condições de saneamento básico, habitação, nutrição e apoio de uma rede social e territorial de suporte. As enfermarias de pediatria e de clínica médica nos hospitais de média complexidade e os chamados hospitais de retaguarda (para assistência hospitalar a pacientes crônicos e de cuidados prolongados) são a melhor demonstração desse tipo de demanda que se expressa de forma inequívoca nos registros de internação hospitalar.

Em paralelo, ao se dedicar prioritariamente à internação de casos agudos por tempo limitado, o hospital tem passado a conviver com constantes proposições de desospitalização e cuidados domiciliares, seja por iniciativa humanizadora, por precaução clínica (na contenção dos processos infecciosos) ou pelo interesse de redução dos gastos públicos e privados. Tal movimento tem levado à própria redefinição dos limites de abrangência do hospital. Assim, ele compreende tanto as enfermarias e unidades de cuidado intensivo, como os ambulatórios de especialidade, que oferecem cirurgia ambulatorial e seguimento para procedimentos que outrora eram realizados sob internação. Indo além, com o processo de desospitalização, o hospital amplia seu território para a casa, através dos programas de atendimento domiciliário, e para a comunidade, através das casas de apoio, que acolhem os doentes de moradia distante, durante tratamentos de alta complexidade nos grandes centros urbanos.

O hospital, ao mesmo tempo em que se desospitaliza, busca a humanização do cuidado oferecido e persegue um caminho ainda recente de discutir que o cuidado técnico seja agregado ao relacional, enfim, que curar (ou não) não seja dissociado de um cuidar humanizado (FERREIRA, 2005).

No que se refere à humanização do cuidado, o Sistema Único de Saúde tem sido alvo de constantes reflexões e propostas de aperfeiçoamento do sistema. A Política Nacional de Humanização (PNH), se propõe a operar transversalmente ao SUS, tendo como intenção "ultrapassar as fronteiras, muitas vezes rígidas, dos diferentes saberes/ poderes que se ocupam da produção da saúde" (BRASIL, 2004, p.2 ). Assim, define como propostas aumentar o grau de co-responsabilidade dos diferentes atores que constituem a rede; realizar uma mudança na cultura dos usuários e promover uma melhor gestão de processos de trabalho. A PNH tem como pressuposto que a Humanização supõe uma troca de saberes, que envolve a todos (equipe, usuários e sua rede social), na busca de desenvolvimento de diálogo, modos de trabalhar em equipe, ampliação dos espaços de troca, levando em conta necessidades e interesses e buscando constituir novos sentidos para todos os sujeitos envolvidos. (BRASIL, 2004).

A PNH na atenção hospitalar, além do elencado acima, demanda a criação de Grupos de Trabalho de Humanização em todos os hospitais com garantia de visita aberta (presença do acompanhante e rede social) e de mecanismos de recepção, acolhimento e escuta. Defende a importância da presença de uma equipe multiprofissional, um conselho gestor local funcionando, com plano de educação permanente. Afirma a importância de serem criados mecanismos de desospitalização dentre os quais os cuidados domiciliares, assim como a garantia dos processos de referência e contra-referência.

Entretanto, se o hospital se desospitaliza e humaniza sua atenção, é a integralidade do cuidado oferecido, o grande desafio para se pensar a gestão, a oferta e a qualidade do atendimento, assim como a própria formação de recursos humanos em saúde. Como Cecílio e Mehry (2003) argumentam, a construção da integralidade, enquanto meta da gestão hospitalar, implica em problematizá-la no hospital e a partir do hospital. A integralidade do cuidado no hospital, entendida pelos autores enquanto a 'síntese dos múltiplos cuidados' disponibilizados pelos diferentes profissionais, remete ao conceito de integralidade enquanto oposição à fragmentação dos saberes e práticas, colocada pelo modelo biomédico de saúde.

Para a construção da integralidade no hospital, dois movimentos são necessários: primeiro, a disponibilização do profissional em realizar uma prática comprometida com a atenção às necessidades de cuidado dos usuários dos serviços em contraposição a uma prática fragmentada em atos e procedimentos, que partem da opção teórico-metodológica do profissional tomada a priori, sem a devida escuta aos sujeitos sob cuidado. Segundo, uma gestão hospitalar que se proponha a articular os cuidados oferecidos ao usuário. Assim, mostra-se necessária uma gestão da micropolítica do trabalho que pense modos de operar o cotidiano institucional possibilitando uma atuação mais solidária e em concerto dos trabalhadores de saúde envolvidos (NICÁCIO, 2003). 
Para a construção da integralidade a partir do hospital, Cecílio e Mehry (2003) ressaltam a importância de se pensála a partir da "transversalidade do cuidado [que] realiza-se em uma rede mais ampla de serviços na qual o hospital é apenas uma estação. " (p. 10, grifo nosso). Problematiza-se assim a auto-suficiência do hospital e sua freqüente desresponsabilização pelo paciente em/após seu momento de alta. Os autores, portanto, argumentam a favor da construção de uma "gestão de forma que a responsabilização pelo cuidado se desse em uma linha de produção do cuidado, contínua e que se transversaliza, atravessando, sem descontinuidade, vários lugares do hospital ou mesmo outros serviços de saúde" (CECÍLIO; MEHRY, 2003, p 11). Assim, um hospital pode ter linhas do cuidado em: saúde da criança e do adolescente, pacientes adultos clínico-cirúrgicos, saúde materno-infantil, maternidade segura ou em crianças portadoras de câncer, por exemplo. A gestão pela linha do cuidado possibilita que esta seja articulada desde as ações da rede básica de saúde, passando pelo hospital, indo a rede de cuidados de reabilitação, por exemplo.

O que é importante que se destaque é que a linha do cuidado acontece sempre em rede, uma noção que também deve ser sempre repensada em seus fluxos e hierarquizações. Reconhecer e qualificar múltiplas portas de entrada na atenção à saúde é garantir acolhimento e atendimento aos segmentos populacionais mais vulneráveis que têm dificuldade de acesso aos serviços sociais e de saúde. Assim, a rede pode ser vista como de arranjo variável ou em círculo. A unidade básica de saúde, a escola e demais equipamentos sociais, os serviços de urgência e emergência e a atenção na enfermaria, podem ser assim reconhecidos como portas de entrada que levam ao cuidado em saúde (CECÍLIO, 1997). Permite-se assim que se articule não apenas a rede de serviços em torno de uma necessidade de saúde, como se articule a própria rede social de suporte.

As linhas do cuidado, a partir do acima apresentado, são instrumentos interessantes não apenas para a gestão da produção do cuidado, mas para uma re-organização dos saberes e práticas do campo da produção da saúde. Não poderiam ser essas linhas de cuidado as linhas da matriz onde se alinhariam os diferentes saberes e práticas do campo da produção da saúde, tal como descrito por Campos (2000)? Não seria uma forma interessante de organização de matriz interdisciplinar da produção de saberes e práticas da saúde?

Essa não poderia ser a matriz através da qual a terapia ocupacional poderia organizar seus próprios saberes e práticas na produção da saúde, deixando para trás a chamada terapia ocupacional 'hospitalar' e assumindo a integralidade do cuidado e a construção de redes (redes de cuidado, redes sociais de suporte, redes de construção permanente de laços de cidadania) como eixo e marca de sua ação?

As reflexões acima nos apontam na direção de pensarmos o lugar do hospital e suas práticas de dentro do campo da produção do cuidado em saúde, no qual a terapia ocupacional é um dos núcleos profissionais. Assim, as práticas privativas e compartilhadas dos vários núcleos profissionais no hospital, devem ser pensadas dentro do contexto mais amplo do campo da produção da saúde, e a partir de linhas do cuidado, se a proposta é se quer construir a integralidade das ações de saúde, considerando o hospital como retaguarda assistencial e apoio à rede de serviços de saúde (ROLLO, 1997) ou como uma 'estação do cuidado' (CECÍLIO; MEHRY 2003) e não o eixo do setor saúde.

\section{CONCLUSÃO}

Um dos aspectos que contribui para a consolidação de práticas e saberes profissionais é quando determinado núcleo profissional é capaz de acumular capital simbólico suficiente para seu reconhecimento por determinado setor ou campo. Tal situação se constata quando as políticas do setor passam a incorporar determinado profissional em sua equipe mínima ou pelo menos reconhecem que o trabalho é qualificado por sua presença. Outro aspecto é quando o núcleo profissional passa a transitar pelas discussões e composições de um determinado campo, passando a compor suas práticas e saberes e, ao mesmo tempo, criando um campo-espelho dentro de seu próprio núcleo profissional. Tem sido assim com a constituição dos campos da Terapia Ocupacional em Saúde Mental, em Saúde e Trabalho, em Gerontologia, em Reabilitação da pessoa com deficiência, e da Terapia Ocupacional Social.

A constituição de um campo-espelho depende, portanto, da capacidade do núcleo profissional escutar, acolher e delimitar com clareza as demandas por seu cuidado e ser capaz de articular e efetivar suas ações, de forma que seu papel seja compreendido e incluído, passando sua contribuição a compor a lista de serviços requisitados pelo campo mais amplo. Para tal, é igualmente essencial o oferecimento de formação continuada na área e a qualificação permanente dos saberes e das práticas desenvolvidos. Por último, sua capitalização simbólica depende da capacidade dos profissionais compartilharem e assim perpetuarem o conhecimento produzido na assistência e na pesquisa através de sua divulgação e publicação em veículos de divulgação científica. Caso contrário, nenhuma qualificação epistemológica acontece e parece que cotidianamente o profissional tem que "inventar a roda".

Esse é o desafio da terapia ocupacional no campo da 
produção do cuidado à saúde, no que tange aos cuidados clínicos e cirúrgicos dos processos saúde-doença. Deixamos aqui de nos referir às práticas hospitalares como um campo. A nosso ver, a terapia ocupacional tem como desafio futuro construir uma abordagem dos processos saúde-doença a partir da perspectiva da integralidade e da humanização do cuidado, do exercício de um olhar menos fragmentador e mais crítico à visão hospitalocêntrica ainda presente. Deve buscar desenvolver escuta e acolhimento às necessidades e problemáticas dos sujeitos sob cuidado, deslocando o hospital do eixo da assistência à saúde e entendendo-o como estação do cuidado. Ao oferecer atenção a partir de linhas do cuidado (à criança e ao adolescente; ao adulto sob cuidados clínicos e cirúrgicos; à saúde materno-infantil; à pessoa com HIV/AIDS, à pessoa com câncer; à pessoa em cuidados paliativos, etc.), as práticas e saberes produzidos pela terapia ocupacional poderão percorrer itinerários nas diferentes linhas passando pela atenção primária, secundária e terciária, e parando em várias 'estações do cuidado'.

A terapia ocupacional assim deve refletir sobre que 'caixas de ferramentas tecnológicas' (MERHY, 2005) possui (ou necessita adquirir) para desenvolver ações de promoção, proteção e recuperação da saúde, de prevenção de agravos e de reabilitação, que venham atender às ne- cessidades de saúde demandadas. Ações que garantam ao sujeito e sua rede social serem compreendidos e cuidados a partir de uma escuta mais ampla de suas necessidades, evitando-se assim tanto abordagens teórico-metodológicas tomadas a priori (a partir da opção de especialidade do terapeuta ocupacional), como racionalidades mais idealizadas do sistema de saúde e menos próximas das necessidades dos seus usuários (quando, por exemplo, desconsidera-se o hospital como lugar também de promoção à saúde).

Para o terapeuta ocupacional, cujo foco de suas ação são as atividades e cotidianos, o cuidado à saúde que disponibiliza se constitui em poder entender e intervir nas manifestações e descontinuidades da cotidianidade ocasionadas por situações diversas de adoecimento, que transitam pelo domicílio, hospital, e/ou por outros equipamentos sociais e de saúde. Assim, cabe a ele/ela refletir cada vez mais sobre qual é o diferencial da terapia ocupacional na abordagem aos processos saúde-doença e às necessidades da população que requer cuidados clínicos e cirúrgicos, construindo ações fundadas na integralidade e na humanização do cuidado, nos diferentes níveis de atenção à saúde, para os diferentes equipamentos sociais e de saúde e, em particular, nessa estação do cuidado, que é o hospital.

GALHEIGO, S. M. Occupational therapy, the production of health care and the place occupied by the hospital: thoughts about the constitution of a field of knowledge and practice. Rev. Ter. Ocup. Univ. São Paulo, v.19, n. 1, p. 20-28, jan./abr. 2008.

\begin{abstract}
This paper intends to argue about the existence of a specific field of occupational therapy in hospital care and its relation to the production of knowledge and practice regarding health care. Through the debate on the concept of field by Bourdieu and by Campos, Chakour e Santos, the article seeks to discuss the production of health care as a dynamic, interdisciplinary and structured field, constituted by institutional relationships, professional core group, other inner groups and social agents. The considerations above lead to the need of thinking the place of the hospital and its practices within the field of health care, in which occupational therapy takes part. Though, the disciplinary and interdisciplinary practices undertaken in the hospital should not be thought outside the major social context inasmuch as there is an intent to construct practices and knowledge out of the integrality (comprehensiveness) of health care, taking into account the hospital as a 'care station'. Presenting the proposal of hospitalar administration following 'care lines', a concept devised by Cecílio and Mehry, the paper proposes the use of the concept as a means of organization of practices and knowledge in the production of health care and in occupational therapy, in favour of practices which effectively come to be based on integrality and the humanization of health care.
\end{abstract}

KEY-WORDS: Occupational therapy. Health-disease process. Comprehensive health care. Humanization of assistance. Hospital care.

\title{
REFERÊNCIAS
}

BONNEWITZ, P. Primeiras lições sobre a sociologia de Pierre

Bourdieu. Rio de Janeiro: Vozes,. 2003
BRASIL. Ministério da Saúde. Secretaria Executiva, Núcleo Técnico da Política Nacional de Humanização. HumanizaSUS: 
política nacional de humanização. Brasília: Ministério da Saúde, 2004.

CAMPOS, G. W. Saúde pública e saúde coletiva: campo e núcleo de saberes e práticas. Ciên. Saúde Coletiva, Rio de janeiro, v.5, n.2, p. 219-230, 2000.

CAMPOS, G.W.; CHAKOUR, M.; SANTOS, R. C. Análise Crítica sobre especialidades médicas e estratégias para integrá-las ao Sistema único de Saúde (SUS). Caderno de Saúde Pública, .Rio de Janeiro, v. 13, n. 1: 141-144, 1997.

CECÍLIO, L. C. Modelos tecno-assistenciais em saúde: da pirâmide ao círculo, uma possibilidade a ser explorada. Caderno de Saúde Pública. Rio de Janeiro, v. 13, n. 3, p. 469-478, 1997.

CECÍLIO, L. C.; MERHY, E. E. Integralidade do cuidado como eixo da gestão hospitalar. Disponível em: http://paginas.terra. com.br/saude/merhy/textos/LivroIntegralidadeIntegralidade $\% 20$ da\%20ateno\%20hospitalar.pdf. Acessado em 01 mar. 2008.

FERREIRA, J. O programa de humanização da saúde: dilemas entre o relacional e o técnico. Saude Sociedade, v. 14, n. 3, p. 111-118, 2005.

GALHEIGO, S. M. A transdisciplinaridade enquanto princípio e realidade das ações de saúde. Revista de Terapia Ocupacional da Universidade de São Paulo, v. 10, n. 2/3, p. 49-54, 1999.
GALHEIGO, S M. A intervenção da terapia ocupacional junto a pessoa sob cuidados clínicos e cirúrgicos: reflexões sobre a cartografia e a constituição de um campo. Revista de Terapia Ocupacional da Universidade de São Paulo, v. 18, n.3, 2007.

MÂNGIA, E. F. Apontamentos sobre o campo da Terapia Ocupacional. Revista de Terapia Ocupacional da Universidade de São Paulo, v. 9, n. 1, p. 5-13, 1998.

MERHY, E. M. Engravidando palavras: o caso da integralidade. Disponível em: htttp://www.nutes.ufrj.br / Home\%20LTC/ doutorado/arquivos/semmerhy.pdf. Acessado em 01 mar. 2008.

NICÁCIO, M. F. Utopia da realidade: contribuições da desinstitucionalização para a invenção de serviços de saúde mental. Campinas, 2003. Tese (doutorado) - DMPS/FCM/Unicamp.

ORTIZ, R. A sociologia de Pierre Bourdieu. São Paulo: Olho D’água, 2003.

ROLLO, A. É possível construir novas Práticas Assistenciais no Hospital Público? In: MERHY, E. E.; ONOCKO, R. Agir em saúde: um desafio para o público. São Paulo: Hucitec; Buenos Aires: Lugar editorial, 1997.

VASCONCELOS, E. M. Complexidade e pesquisa interdisciplinar. Petrópolis: Vozes, 2004. 